\title{
Vitamin K2 augments 5-fluorouracil-induced growth inhibition of human hepatocellular carcinoma cells by inhibiting NF-kB activation
}

\author{
HAO ZHANG $^{1,2}$, IWATA OZAKI ${ }^{2,3}$, HIROSHI HAMAJIMA ${ }^{2}$, SHINJI IWANE $^{2}$, HIROKAZU TAKAHASHI $^{2}$, \\ YASUNORI KAWAGUCHI ${ }^{2}$, YUICHIRO EGUCHI ${ }^{2}$, KYOSUKE YAMAMOTO $^{4}$ and TOSHIHIKO MIZUTA ${ }^{2}$ \\ ${ }^{1}$ Department of Surgery, The First Affiliated Hospital, China Medical University, Shenyang 110001, P.R. China; \\ ${ }^{2}$ Department of Internal Medicine, and ${ }^{3}$ Health Administration Center, Saga Medical School, Saga University, 5-1-1 \\ Nabeshima, Saga 849-8501; ${ }^{4}$ Takagi Hospital, 141-11 Sakemi Ohkawa City, Fukuoka 831-0016, Japan
}

Received June 16, 2010; Accepted September 7, 2010

DOI: 10.3892/or_00001056

\begin{abstract}
Although 5-fluorouracil (5-FU) is one of the most commonly used chemotherapeutic agents in various cancer including hepatocellular carcinoma (HCC), chemoresistance has precluded single use of 5-FU in clinical settings. Since menatetrenone, an analogue of vitamin K2 (VK2), inhibits growth of cancer cells including HCC cells in vitro and in vivo, we examined $\mathrm{VK} 2$ modulation of $\mathrm{HCC}$ cell response to 5-FU. VK2 pretreatment dose-dependently enhanced growth-inhibition by 5-FU through a G1 cell cycle arrest. $\mathrm{VK} 2$ inhibited 5-FU-induced NF- $\mathrm{B}$ activation and cyclin D1 expression. Therefore, combination of VK2 and 5-FU might represent a new therapeutic strategy for patients with HCC.
\end{abstract}

\section{Introduction}

Among chemotherapeutic agents against hepatocellular carcinoma (HCC), most commonly used 5-fluorouracil (5-FU) possesses significant cell-killing activity. Yet as with other anticancer agents, chemoresistance is a major clinical obstacle to successful 5-FU chemotherapy for HCC patients. Among various factors that confer chemoresistance, attention has focused on transcription factor nuclear factor (NF)- $\mathrm{BB}$, which promotes tumor development and progression mainly by enhancing cell proliferation and interfering with apoptosis (1-3). Anticancer drugs have been reported to induce the nuclear translocation and DNA binding activity of NF- $\mathrm{NB}$ in cancer cells. This drug-induced NF- $\mathrm{B}$ activity inhibits killing of cells by the chemotherapeutic agents $(4,5)$. Furthermore, inhibition of NF- $\mathrm{KB}$ activity by transfecting dominant-negative I $\mathrm{B} \alpha$ has been shown to enhance the cytotoxicity of anti-

Correspondence to: Dr Iwata Ozaki, Health Administration Center, Saga Medical School, Saga University, 5-1-1 Nabeshima, Saga 849-8501, Japan

E-mail: ozaki@cc.saga-u.ac.jp

Key words: hepatocellular carcinoma, 5-fluorouracil, vitamin K2,

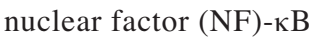

cancer drugs in vitro and in vivo $(2,4,6)$. These results implicate $\mathrm{NF}-\kappa \mathrm{B}$ in resistance to cancer treatment, suggesting importance of finding ways to reduce $\mathrm{NF}-\kappa \mathrm{B}$ activity induced by anticancer drugs.

Menatetrenone is an analogue of vitamin K2 (VK2), first identified as a critical factor in blood coagulation and a cofactor in bone metabolism. VK2 has been found to inhibit in vitro and in vivo growth of cancer cells including glioma, lung cancer, leukemia, and HCC cells (7-10). Cell cycle arrest and apoptosis are believed to be involved in this action of VK2, but precise molecular mechanisms underlying VK2-induced growth inhibition and killing in HCC cells remain to be elucidated. Recently VK2 also was found to inhibit hepatoma cell invasiveness and metastasis (11). More importantly, we recently demonstrated that administration of VK2 to HCC patients significantly decreased recurrence of HCC after curative local ablation therapy (12). Habu et al (13) reported that VK2 suppressed development of HCC from the cirrhotic liver in patients infected with hepatitis virus. These observations strongly suggest that VK2 has profound influence on HCC development and progression. We reported that $\mathrm{VK} 2$ inhibited $\mathrm{HCC}$ cell proliferation by down-regulating cyclin D1 through the inhibition of NF- $\mathrm{BB}$ activation (14). Although these results obtained with VK2 in experimental and clinical studies are promising, one question is whether VK2 could impede development of chemotherapyinduced drug resistance to preserve 5-FU cytotoxicity in HCC.

In the present study we examined the effects of combined 5-FU and VK2 treatment on growth of HCC cells. Our results indicated that VK2 pretreatment rendered tumor cells more susceptible to growth inhibition by 5-FU. Enhancement of growth-inhibitory effect was related to increased G1 cell cycle arrest involving suppression of $\mathrm{NF}_{-} \mathrm{\kappa B}$ activation and cyclin D1 expression by VK2. Combining VK2 with conventional chemotherapy such as 5-FU treatment might improve outcome in HCC patients.

\section{Materials and methods}

Cells and reagents. The human HCC cell lines HepG2, Huh7, HLE, and Hep3B were obtained from the Japanese 
Cancer Research Resources Bank (Osaka, Japan). Cells were cultured and maintained in Dulbecco's modified Eagle's medium (DMEM) (Invitrogen, Carlsbad, CA) containing $10 \%$ fetal calf serum (Invitrogen). 5-FU was purchased from Sigma (St. Louis, MO). Menatetrenone, a VK2 analogue, was obtained from Eisai (Tokyo, Japan). Dominant-negative Iк $\mathrm{B} \alpha$ vector was purchased from Clontech Laboratories (Mountain View, CA).

Cell proliferation assay. Cell growth was determined by the WST-1 proliferation assay kit (Takara, Kyoto, Japan) as previously described (14). Cells were seeded in 24-well culture plates at a density of $1 \times 10^{4}$ cells/well, and incubated at $37^{\circ} \mathrm{C}$ for $24 \mathrm{~h}$. After various treatments, the cells were incubated further for $48 \mathrm{~h}$. Then the cells were incubated with the WST-1 reagents, and absorbance of formazan products at $450 \mathrm{~nm}$ was measured with a CS-9300 microtiter plate reader (Shimadzu, Tokyo, Japan).

Incorporation of 5-bromo-2'-deoxyuridine (BrdU) into DNA was measured with a colorimetric BrdU cell proliferation ELISA kit (Boehringer Ingelheim, Ingelheim, Germany) according to the manufacturer's instructions. Cells were seeded in 24-well culture plates at a density of $10^{4}$ cells/well, incubated at $37^{\circ} \mathrm{C}$ for $24 \mathrm{~h}$, and incubated further with various treatments for the next $48 \mathrm{~h}$. Then BrdU labeling solution was added and incubation was continued for $8 \mathrm{~h}$ at $37^{\circ} \mathrm{C}$. Then, FixDenat solution from the kit was added for $30 \mathrm{~min}$ at room temperature, followed by addition of anti-BrdU-POD solution for $90 \mathrm{~min}$ at room temperature. At the end of the assay, substrate solution was added to each well. After a 15-min incubation at room temperature, absorbance of the samples was assessed at $370 \mathrm{~nm}$ with a reference wavelength of $492 \mathrm{~nm}$ using the CS-9300PC microtiter plate reader (Shimadzu).

FACS analysis. FACS analysis of propidium iodide (PI)stained nuclei was performed as previously described $(14,15)$. Briefly, cells were plated at a density of $2 \times 10^{5}$ cells/well in 6 -well dishes, and incubated at $37^{\circ} \mathrm{C}$ for $24 \mathrm{~h}$. Then the cells were incubated further with 5-FU, VK2, or both for $24 \mathrm{~h}$. The cells were then harvested by trypsinization, collected by centrifugation, and suspended in hypotonic lysis buffer $(0.1 \%$ Triton $\mathrm{X}-100$ in phosphate-buffered saline $), 0.1 \mathrm{mg} / \mathrm{ml}$ RNase, and $40 \mu \mathrm{g} / \mathrm{ml} \mathrm{PI}$. After $30 \mathrm{~min}$ at $37^{\circ} \mathrm{C}$, the cells were analyzed with a FACSCalibur fluorocytometer (BectonDickinson, Franklin Lakes, NJ) to determine the percentages of hypodiploid and diploid cells.

Assessment of apoptosis. For analysis of DNA laddering characteristic of apoptotic cell death, DNA was isolated from cells treated with 5-FU, VK2, or both after 48 h. Cells were resuspended in lysis buffer containing $10 \mathrm{mM}$ EDTA, $10 \mathrm{mM}$ Tris ( $\mathrm{pH} 8.0$ ), and $0.5 \%$ Triton $\mathrm{X}-100$ at $4^{\circ} \mathrm{C}$ for $10 \mathrm{~min}$ and centrifuged at $16,000 \mathrm{rpm}$ for $20 \mathrm{~min}$. The supernatant was treated with RNase A at $37^{\circ} \mathrm{C}$ for $1 \mathrm{~h}$ and proteinase $\mathrm{K}$ at $50^{\circ} \mathrm{C}$ for $30 \mathrm{~min}$ and then precipitated with isopropanol. The DNA was resuspended, and electrophoresed in a $2 \%$ agarose gel at $50 \mathrm{~V}$ for $3 \mathrm{~h}$. DNA was visualized by ethidium bromide staining and photographed under ultraviolet light. Morphologic changes in the nuclear chromatin of cells undergoing apop- tosis were detected by staining with Hoechst 33342 (Wako, Osaka, Japan). Briefly, cells were plated in 96-well plates ( $2 \times 10^{5}$ cells/well); treated with 5 -FU, VK2, or both for $24 \mathrm{~h}$; stained with Hoechst 33342, and then observed using fluorescence microscopy. One thousand cells were observed in five randomly chosen fields. Cells with condensed or fragmented nuclei were considered apoptotic.

Electrophoretic mobility shift assay (EMSA). NF-кB activity in nuclei isolated from hepatoma cells was determined by electrophoretic mobility shift assay (EMSA). The extraction of nuclear and cytoplasmic proteins and EMSA were performed as described previously $(14,15)$. Briefly, $5 \mu \mathrm{g}$ of nuclear protein was incubated for $30 \mathrm{~min}$ at room temperature with binding buffer (20 mM HEPES-NaOH, pH 7.9, 2 mM EDTA, $100 \mathrm{mM} \mathrm{NaCl}, 10 \%$ glycerol, $0.2 \%$ NP-40), poly (dI-dC), and ${ }^{32} \mathrm{P}$-labeled double-strand oligonucleotide containing the NF-кB binding motif (Promega Corp., Madison, WI, USA). The double-stranded oligomer used for EMSA had the sequence: 5'-AGTTGAGGGGACTTTCCCAGGC-3' (only the sense strand is shown). Reaction mixtures were loaded onto a $4 \%$ polyacrylamide gel and electrophoresed with a running buffer of $0.25 \mathrm{X}$ TBE. After the gel had dried, DNA-protein complexes were visualized by autoradiography. Intensity of electrophoretic bands was measured using a BAS 2000 image analyzer (Fujifilm, Tokyo, Japan).

Western blotting. Protein expression of p65, p18, p21, p27, cyclin D1, and B-actin were investigated by Western blotting. Cells $\left(2 \times 10^{6}\right)$ were collected and lysed with extraction buffer containing $50 \mathrm{mM}$ Tris ( $\mathrm{pH} 7.5), 150 \mathrm{mM} \mathrm{NaCl}, 0.1 \%$ SDS, $5 \mathrm{mM}$ EDTA $(\mathrm{pH} 8.0), 1 \mathrm{mM}$ PMSF, $10 \mu \mathrm{g} / \mathrm{ml}$ trypsin inhibitor, and $50 \mathrm{mM}$ iodoacetamide. After $30 \mathrm{~min}$ at $4^{\circ} \mathrm{C}$, cell debris was eliminated by centrifugation at $15,000 \mathrm{rpm}$ for $20 \mathrm{~min}$, and the supernatant was collected. After measurement of protein concentration using a protein assay kit (Bio-Rad, Hercules, CA), $40 \mu \mathrm{g}$ of protein was mixed with sodium dodecyl sulfate (SDS) sample buffer, separated by SDSpolyacrylamide gel electrophoresis (PAGE), and transferred to a polyvinylidene difluoride membrane (Bio-Rad), which was blocked overnight with $0.1 \%$ Tween and $5 \%$ skim milk. Membranes were incubated with anti-p65, p18, p21, p27, and cyclin D1 antibodies (Santa Cruz Biotechnology, Santa Cruz, CA) in PBS with $1 \%$ bovine serum albumin (BSA) for $1 \mathrm{~h}$. Anti-human B-actin antibody (Biomedical Technologies, Stoughton, MA) was used as a control. Membranes were washed 3 times with $0.1 \%$ Tween-20 in PBS and stained with horseradish peroxidase-conjugated secondary antibody. All immunoblots were visualized using an enhanced chemiluminescence system (Amersham, Buckinghamshire, UK) according to the manufacturer's instructions.

$R N A$ isolation and semiquantitative reverse transcription-polymerase chain reaction ( $R T-P C R)$. Total RNA was extracted from cultured hepatoma cells using ISOGEN (Nippon Gene, Tokyo, Japan) according to the manufacturer's instructions. RNA concentration was determined spectrophotometrically, and integrity of all samples was confirmed by visualizing $28 \mathrm{~S}$ and $18 \mathrm{~S}$ ribosomal RNA bands under ultraviolet light after gel electrophoresis. Semiquantitative RT-PCR for p21, 

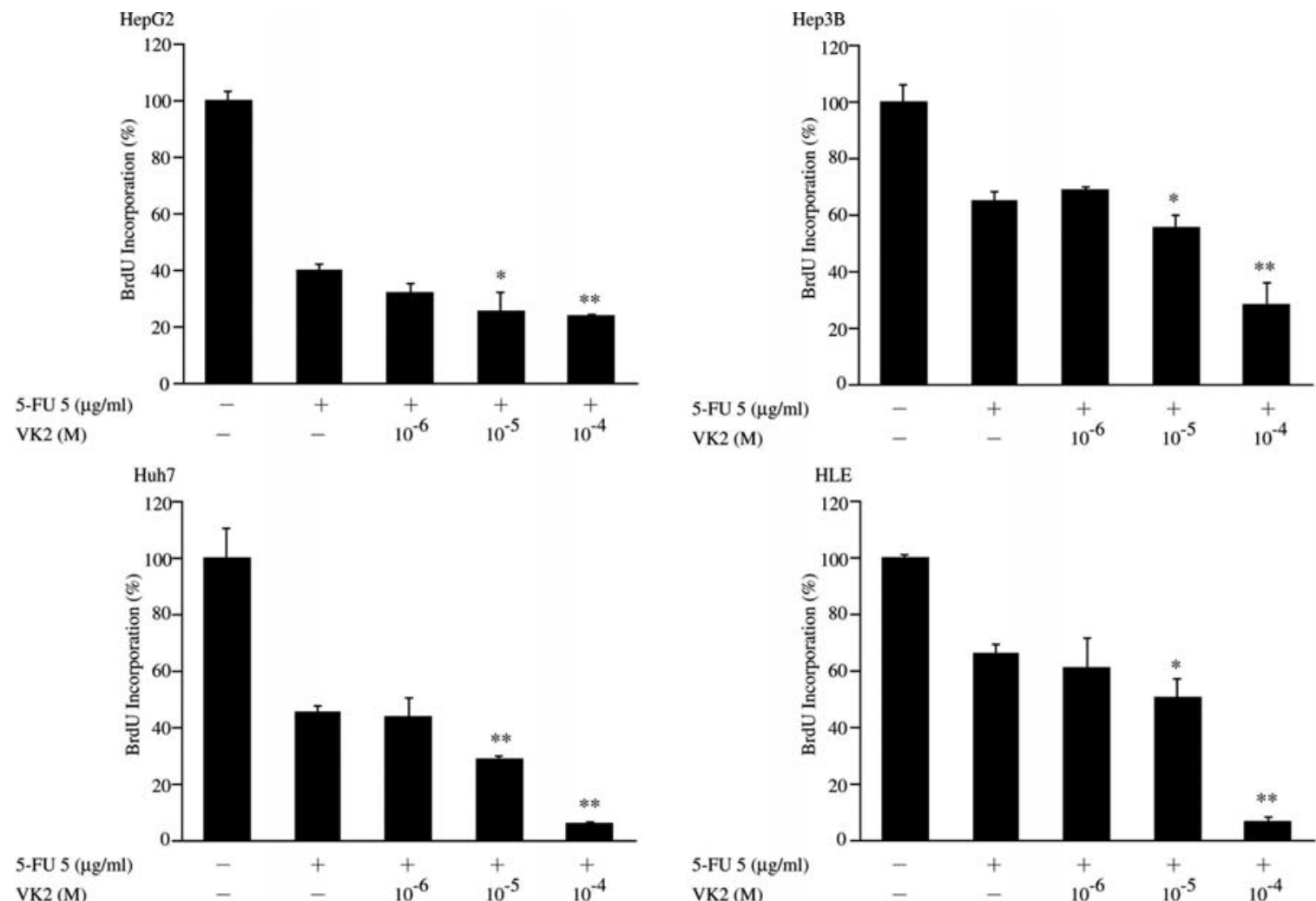

Figure 1. VK2 enhances 5-FU-induced growth inhibition in HCC cells. Cells were incubated in 5-FU (5 $\mu \mathrm{g} / \mathrm{ml})$ with or without various concentrations of VK2 for $48 \mathrm{~h}$. Cell proliferation was then determined by detection of BrdU incorporation. Results are expressed as percentages of the incorporation seen in HCC cells without any treatment. Data are shown as the mean \pm SD from 3 independent experiments. ${ }^{*} \mathrm{P}<0.05,{ }^{* *} \mathrm{P}<0.01$ compared with cells treated with 5 -FU alone.

p27, cyclin D1 and GAPDH was performed as described previously (14).

Luciferase reporter gene assay. Luciferase assays were performed using the method described by the manufacturer (Dual-Luciferase Reporter Assay System; Promega). Briefly, cells were seeded onto 24 -well plates at $10^{4}$ cells/well without antibiotics. After $24 \mathrm{~h}$, cells were washed twice with OptiMEM medium (Life Technologies, Rockville, MD), followed by the addition of $0.5 \mathrm{ml}$ of Opti-MEM medium containing

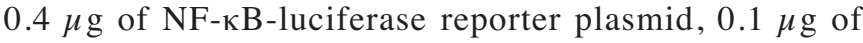
control luciferase plasmid, and $4 \mu 1$ of Lipofectamine reagent (Invitrogen). After 4-h incubation, the medium was changed to a fresh medium, again free of antibiotics. Then cells were treated with 5-FU with or without VK2 for $12 \mathrm{~h}$, washed twice with PBS, and carefully scraped into $1 \mathrm{X}$ passive lysis buffer. Cell extracts were immediately assayed for luciferase activity using a Berthold Luminometer (MLR-100 Micro Lumino Reader, Corona Electric, Ibaragi, Japan).

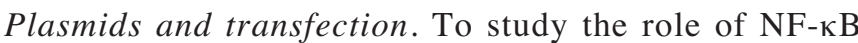
induced by $5-\mathrm{FU}$ in hepatoma cell proliferation, hepatoma cells were transiently transfected with dominant-negative $\mathrm{I} \kappa \mathrm{B} \alpha$ p65 subunit of $\mathrm{NF}-\kappa \mathrm{B}$, or empty vector. The plasmid encoding dominant-negative $\mathrm{I} \kappa \mathrm{B} \alpha$ was purchased from Clontech Laboratoires. Plasmid encoding p65 NF- $\mathrm{BB}$ subunit was described previously (14). HCC cells were transfected using Lipofectamine reagents (Invitrogen) according to the manufacturer's instructions. For proliferation analysis, cells were treated with 5-FU for $6 \mathrm{~h}$ after transfection, and then further incubated for $48 \mathrm{~h}$. Subsequently, cell growth was examined by WST-1 proliferation assay.

Statistical analysis. Differences were analyzed using Student's t-test, and a p-value $<0.05$ was considered indicative of significance. All experiments were performed in triplicate as a minimum. Data are shown as the mean \pm standard deviation (SD).

\section{Results}

VK2 enhanced 5-FU-induced growth inhibition in HCC cells through cell cycle arrest at G1. To investigate whether VK2 altered susceptibility of cells to 5-FU, HCC cells were treated with various concentrations of VK2 prior to 5-FU $(5 \mu \mathrm{g} / \mathrm{ml})$. BrdU incorporation during DNA synthesis by these cells was then assayed. As shown in Fig. 1, DNA synthesis of HCC cells was inhibited by $5 \mu \mathrm{g} / \mathrm{ml}$ of $5-\mathrm{FU}$ alone to $40-70 \%$ of synthesis in control. Preincubation with VK2 dose-dependently enhanced the growth-inhibitory effect of 5-FU. Similar findings were observed when cell survival was quantitated by the WST-1 proliferation assay (data not shown).

To determine the mechanism of VK2-enhanced growth inhibition in HCC cells, FACS analysis was performed to examine whether cells arrested in a specific phase of the cell cycle. As shown in Fig. 2, the percentage of cells in G1 was significantly increased following treatment with 5-FU plus VK2 compared to 5-FU alone in HepG2 cells, showing $3.6,10.2$, and $19.3 \%$ induction of G1 cells in response to $10^{-6}$, $10^{-5}$, and $10^{-4} \mathrm{M}$ of $\mathrm{VK} 2$, respectively. The proportion of pre- 

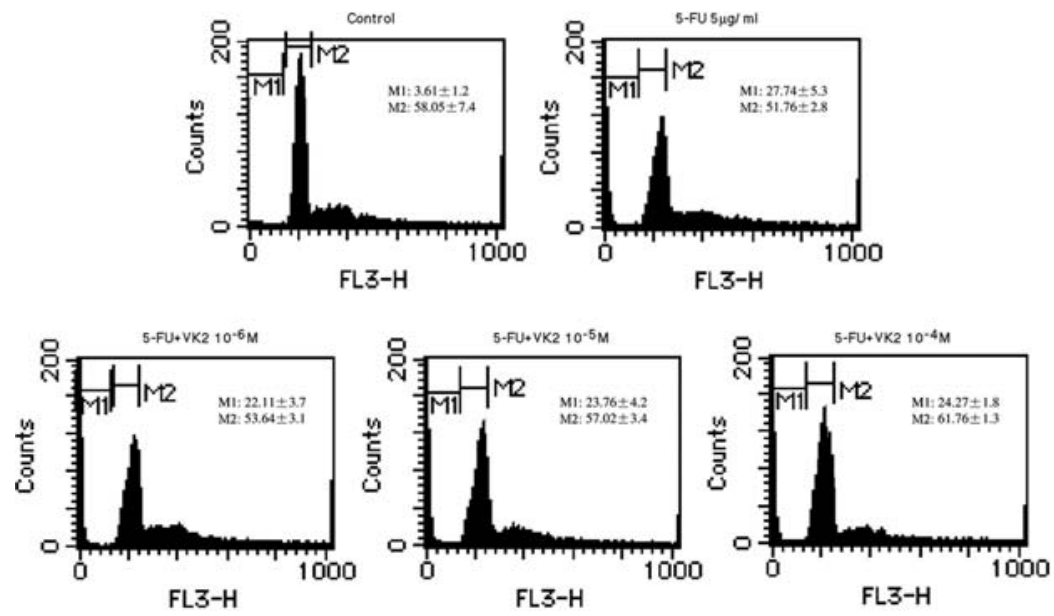

Figure 2. VK2 enhances 5-FU-induced growth inhibition by inducing G1 cell cycle arrest in Hep3B cells. Cells were incubated in 5-FU (5 $\mu \mathrm{g} / \mathrm{ml})$ with or without various concentrations of VK2. After $48 \mathrm{~h}$ of incubation, cells were collected and stained with PI. DNA content was analyzed by FACS. Histograms represent total DNA content, percentages of cells in pre-G1 and G1 phases are shown as M1 and M2, respectively.

A

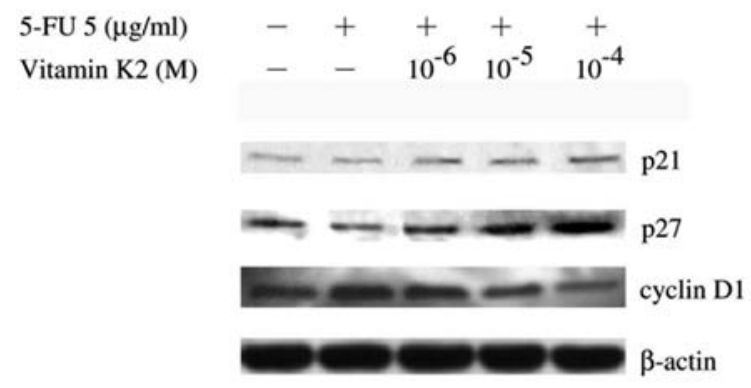

B

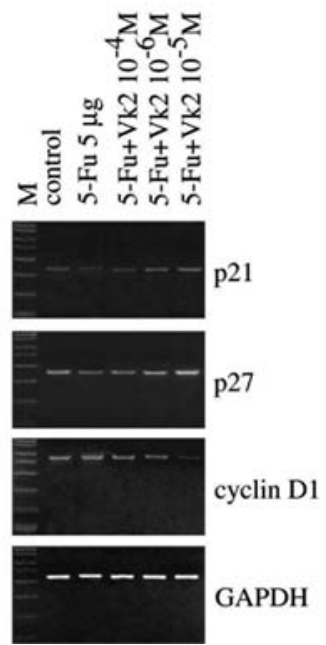

Figure 3. VK2 up-regulates 5-FU-induced p21 and p27 reduction and inhibits 5-FU-induced cyclin D1 promotion. (A) Cells were treated with 5-FU with or without various concentrations of VK2 for 48 h. Forty micrograms of extracted total cell lysate was used for Western blot analysis of p18, p21, p27, cyclin D1, or B-actin. (B) Cells were treated with 5-FU with or without various concentrations of VK2 for $24 \mathrm{~h}$, and transcription of p21, p27, and cyclin D1 was determined by RT-PCR. Glyceraldehyde 3-phosphate dehydrogenase (GAPDH) expression was used as a control. M, 100-base-pair DNA molecular marker.

G1 cells, presumably apoptotic cells, did not differ between 5-FU alone and in combination with VK2. This result was supported in findings by DNA laddering and Hoechst 33342 staining (data not shown). Similar results were obtained in Huh7, HLE, and Hep3B cells.

VK2 decreases 5-FU-induced cyclin D1 expression and counteracts reduction of cyclin-dependent kinase (Cdk) inhibitor expression by 5-FU in HCC cells. The above FACS analyses indicated that VK2 increased 5-FU-induced growth inhibition through a G1 arrest in the cell cycle. We next examined by Western blot analysis whether VK2 affects the G1 cell cycle control protein cyclin D1 and the Cdk inhibitors p18, p21, and p27. As shown in Fig. 3A, inhibition of p21 and p27 and slight induction of cyclin D1 were observed after exposure to 5-FU alone, while p18 was not changed. When cells were treated with 5-FU plus VK2, significant reduction in cyclin D1 expression and induction in p21 and p27 expression were observed. Expression of p18 did not change in treated cells. Further, when mRNA expression for cyclin D1, p21, and p27 was examined by RT-PCR, and pattern of change was similar to that seen by Western blotting (Fig. 3B), indicating that expression of these cell cycle regulatory proteins was regulated at the mRNA level by combined treatment with 5-FU plus VK2.

$V K 2$ inhibits 5-FU-induced $N F-\kappa B$ activation in HCC cells. Since NF- $\mathrm{NB}$ is essential to up-regulation of proliferation in various cell types (1-3) and cyclin D1 is known to be upregulated by $\mathrm{NF}-\kappa \mathrm{B}$, we investigated involvement of $\mathrm{NF}-\kappa \mathrm{B}$ activity in the VK2-mediated increase in susceptibility of HCC cells to growth inhibition by 5 -FU by performing EMSA to assess DNA-binding activity. Western blotting to detect nuclear translocation, and a luciferase reporter gene assay to determine promotion of transcriptional activity, also were carried out. As shown in Fig. 4A, Hep3B cells constitutively showed NF-кB DNA-binding activity. Treatment with 5-FU alone increased this NF- $\mathrm{BB}$ binding 
A
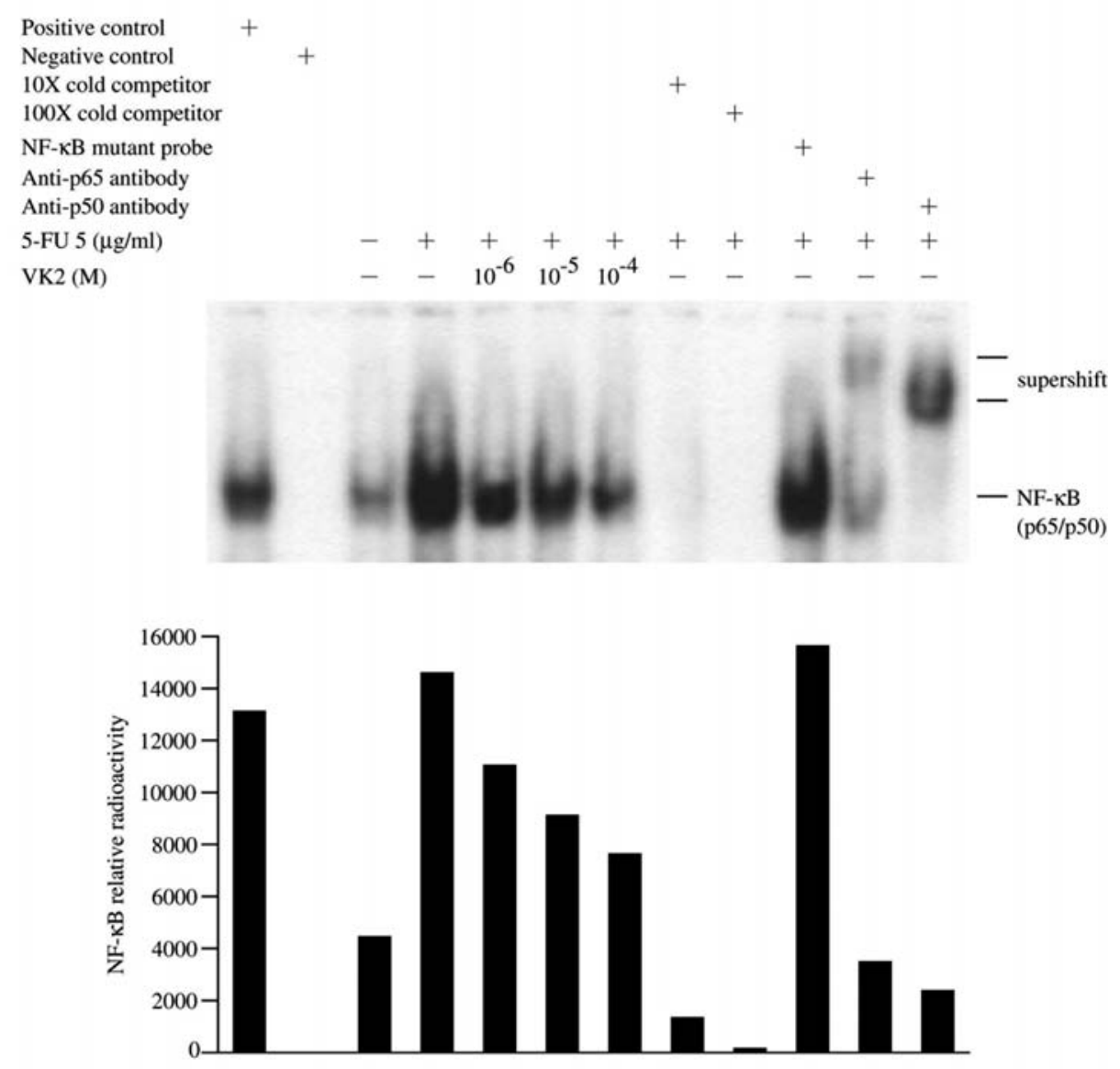

B
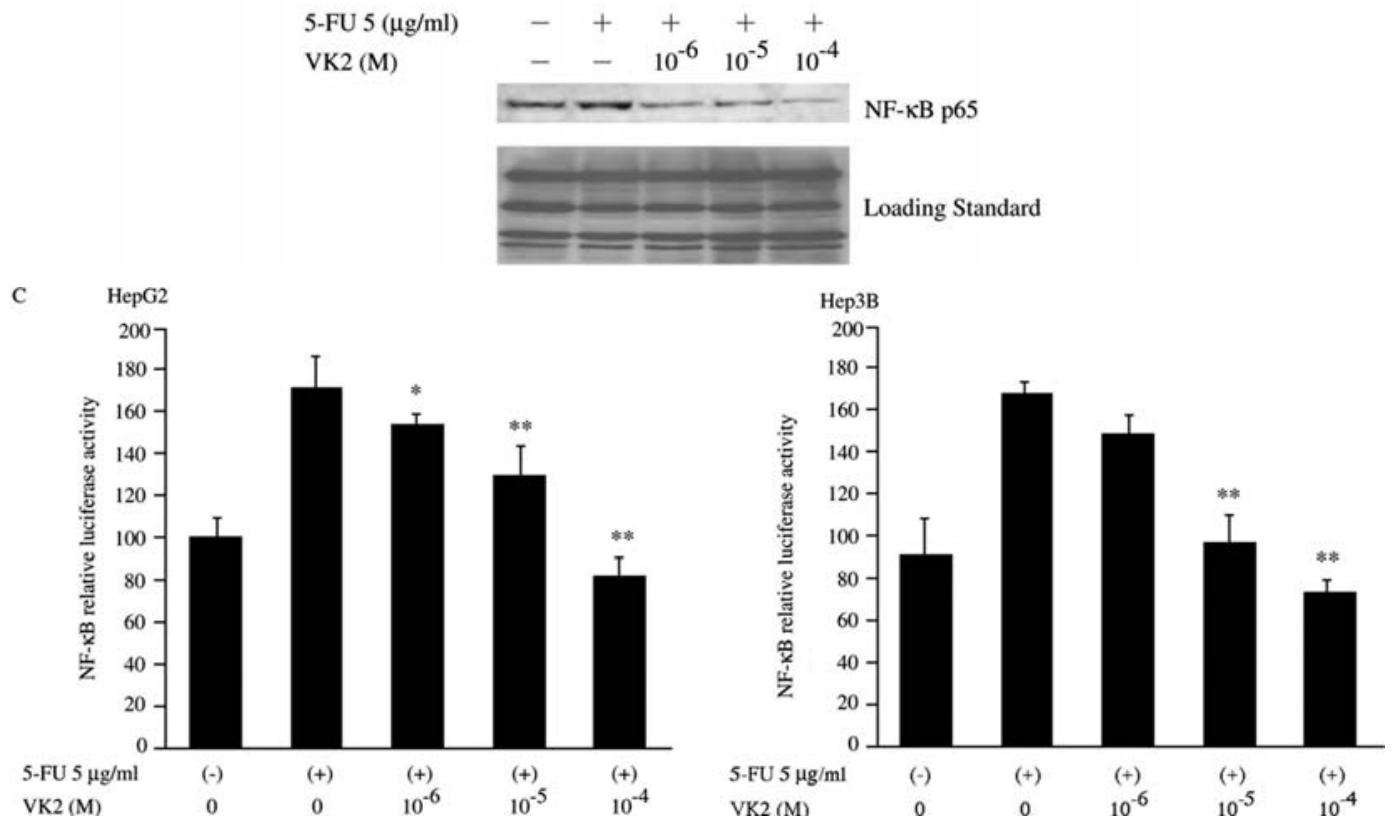

Figure 4. VK2 inhibits 5-FU-induced NF-кB activation in Hp3B cells. (A) After cells were incubated in 5-FU (5 $\mu \mathrm{g} / \mathrm{ml})$ with or without various concentrations of VK2 for $12 \mathrm{~h}$, nuclear protein was extracted for analysis of NF-kB binding activity by electrophoretic mobility shift assay (EMSA). Quantitative analysis of NF- $\mathrm{kB}$ bands measured by BAS 2000 is presented in the lower panel, which is a representative result among 3 similar experiments. (B) VK2 inhibited 5-FU-induced p65 nuclear translocation. Cells were treated with 5-FU with or without various concentrations of VK2. The p65 protein expression in nuclear extracts was detected by Western blotting. Nuclear protein loading was standardized by Coomassie blue staining. (C) VK2

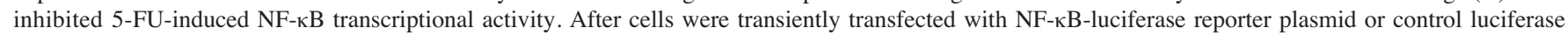
plasmid for $4 \mathrm{~h}$, cells were treated with 5-FU with or without various concentrations of VK2 for $12 \mathrm{~h}$. The luciferase activity was measured by a DualLuciferase Reporter Assay System. Data are shown as the mean \pm SD obtained from 3 independent experiments. ${ }^{*} \mathrm{P}<0.05,{ }^{* *} \mathrm{P}<0.01$ compared with the cells treated with 5-FU alone. 


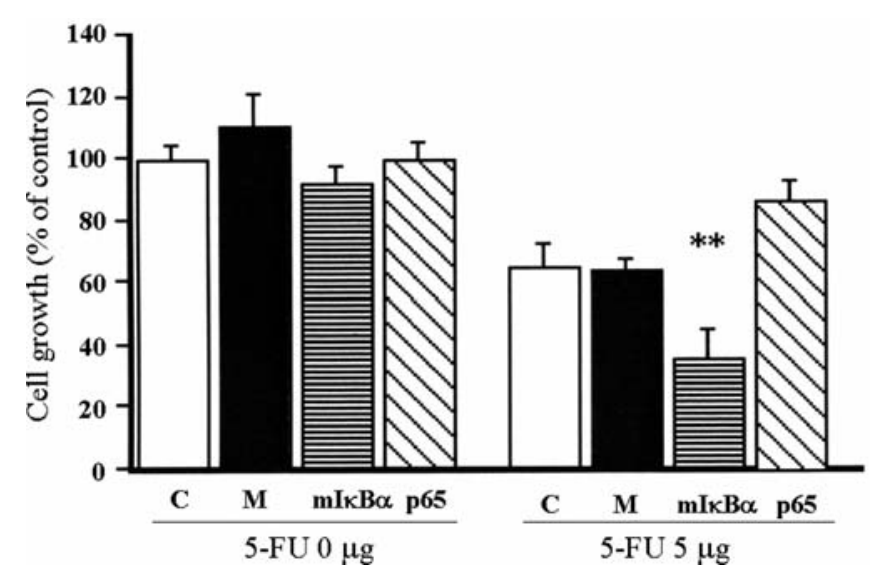

Figure 5. Inhibition of NF-кB activation potentiates 5-FU-induced growth inhibition in Hep3B cells. Cells were transiently transfected with mutant $\mathrm{mI} \kappa \mathrm{B} \alpha$ the p65 subunit of $\mathrm{NF}-\kappa \mathrm{B}$, or empty vector (mock, or M). After 6-h transfection, cells were stimulated with $5 \mu \mathrm{g} / \mathrm{ml}$ of $5-\mathrm{FU}$ and incubated for another $48 \mathrm{~h}$. Then cell growth was determined using a WST-1 proliferation assay. Data are presented as the mean \pm SD from 3 independent experiments ${ }^{* *} \mathrm{P}<0.01$ compared with control $(\mathrm{C})$, mock transfection and $\mathrm{p} 65$ transfection.

activity further. Induction of NF-кB activation by 5-FU was potently suppressed by addition of VK2. An excess of unlabeled NF- $\mathrm{KB}$ probe (10-fold and 100-fold), but not an $\mathrm{NF}-\kappa \mathrm{B}$ mutant probe abolished the binding of NF- $\kappa \mathrm{B}$, demonstrating that binding of the $\mathrm{NF}-\kappa \mathrm{B}$ probe was specific. Furthermore, results of a supershift assay suggested that the 5-FU-activated complex consisted of p50 and p65 subunits. Densitometric analysis of the autoradiographic bands showed that combined treatment with 5-FU and $10^{-6}, 10^{-5}, 10^{-4} \mathrm{M}$ of VK2 decreased 5-FU-induced NF-кB activation by 25, 38, $49 \%$, respectively (Fig. 4A, lower panel).

To test the effect of 5-FU and VK2 on expression of nuclear p65 subunit, a major component of NF-KB activity, cells were exposed to 5-FU with or without various concentrations of VK2. As shown in Fig. 4B, 5-FU increased amounts of p65 in nuclei of Hep3B cells. Consistent with results observed by EMSA, VK2 reduced this effect upon nuclear p65 protein in a dose-dependent manner. Equivalent nuclear protein loading in each lane was verified by Coomassie blue staining.

To determine the effect of VK2 on 5-FU-induced NF-кB transcriptional activity, we transiently transfected the HCC cells with an NF-кB luciferase reporter gene construct, having treated some of them with VK2 for $2 \mathrm{~h}$ before 12-h treatment with 5-FU. With 5-FU treatment alone luciferase activity was about 1.8-times higher than in untreated controls. Preincubation of Hep3B cells with VK2 prior to 5-FU abolished this induction of luciferase expression by 5-FU (Fig. 4C).

Inhibition of $N F-\kappa B$ by mutant I $\kappa$ B $\alpha$ transfection augments 5-FU-induced growth inhibition in HCC cells. To determine whether activation of $\mathrm{NF}-\mathrm{\kappa B}$ by $5-\mathrm{FU}$ is directly associated with 5-FU-induced growth inhibition in hepatoma cells, we examined the effect of mutant Iк $\mathrm{B} \alpha$ which is resistant to degradation and inhibits translocation of $N F-\kappa B$ to the nucleus, upon proliferation of cells exposed to 5-FU. After introduction of mutant IкB $\alpha$ into cells by transient trans- fection, we stimulated cells with 5 -FU for $48 \mathrm{~h}$, then examining the cell growth using a WST-1 proliferation assay. As shown in Fig. 5, transfection of mutant IкB $\alpha$ enhanced growth inhibition in 5-FU-treated Hep3B cells, while vector control did not augment 5-FU-induced growth inhibition in Hep3B cells. When HCC cells were transfected with the p65 subunit of NF-кB, $5 \mu \mathrm{g} / \mathrm{ml}$ of 5-FU failed to inhibit cell growth. These results suggested that $\mathrm{NF}-\kappa \mathrm{B}$ activation antagonized 5-FU- and VK2-induced growth inhibition in HCC cells.

\section{Discussion}

HCC is highly resistant to currently available chemotherapeutic regimens including those with 5-FU. In the present study, pretreatment of HCC cells with VK2 resulted in significant enhancement of 5-FU-mediated growth inhibition of cells. Furthermore, the results suggested a possible signal transduction mechanism underlying VK2 enhancement of growth inhibition. VK2 inhibited activation of NF-кB otherwise induced by 5-FU, and up-regulated $\mathrm{Cdk}$ inhibitors as well as down-regulating cyclin D1. The result was cell cycle arrest in G1. Thus, our findings delineate a possible mechanism for synergistic induction of growth inhibition by 5 -FU given in combination with VK2 .

While 5-FU is the first-line drug in chemotherapy of HCC, chemoresistance is the major obstacle to successful 5-FU chemotherapy. In an effort to improve the therapeutic index of 5-FU, several investigators have studied efficacy of 5-FU combined with other agents such as cisplatin, methotrexate, and doxorubicin in the treatment of patients with HCC, but use of multiple chemotherapeutic agents in these patients induced various degrees of toxicity (16-18). Although combination therapy using 5-FU and IFN- $\alpha$ has shown effectiveness in HCC, disagreement was reported by some investigators (19-21). High associated costs limit extensive use of IFN- $\alpha$ combination regimens in clinical treatment, particularly in developing countries. Our results indicated that combined treatment with VK2 may enhance sensitivity to 5-FU in HCC cells, without problems of toxicity that are typical of other combined regimen including 5-FU. Thus, VK2 might be uniquely beneficial in combination with 5-FU in chemotherapy for patients with HCC.

VK2 has been reported to show anticancer effects inducing apoptosis and cell cycle arrest in several tumor cell types such as leukemia cells, osteosarcoma cells, HCC cells, glioma cells, and lung cancer cells, also a number of striking anecdotal clinical reports supports use of VK2 as an anticancer agent $(7-13,22)$. However, therapies combining VK2 with established anti-tumor agents have not been investigated. Our present results showed augmentation of cell growth suppression induced by 5-FU in HCC cells by adding VK2.

To determine how VK2 enhances 5-FU-induced growth inhibition, we investigated the activity of $\mathrm{NF}-\kappa \mathrm{B}$, a key mediator in promoting proliferation and inhibiting apoptosis. We found that exposure of cells to 5-FU alone activated $\mathrm{NF}-\kappa \mathrm{B}$ activity in a dose- and time-dependent manner (data not shown). Several chemotherapeutic agents such as daunorubicin, cisplatin, and paclitaxel have been reported to 
activate NF- $\mathrm{KB}$ in HCC cells, resulting in marked suppression of the cell-killing activity of the tested drug $(23,24)$. We first demonstrated that 5-FU induced $\mathrm{NF}-\kappa \mathrm{B}$ activation in $\mathrm{HCC}$ cell lines, ruling out inhibition of $\mathrm{NF}-\kappa \mathrm{B}$ as a mechanism for 5 -FU-induced growth inhibition. Indeed, $\mathrm{NF}-\kappa \mathrm{B}$ activation after chemotherapeutic treatments has been reported in various tumor cell lines, presumably representing a defense mechanism tending to counteract the cell death cascades inhibited by these cancer therapies $(2,4,25)$. This NF-кBbased defense therefore represents a potentially important molecular target in enhancing sensitivity of certain cancer cells that otherwise show resistance to various drugs. Our results showed that a VK2 analogue, on the other hand, significantly inhibited NF- $\mathrm{\kappa B}$ activity in 5-FU treated cells in a dose-dependent manner, including NF- $\mathrm{KB}$ nuclear translocation, DNA binding activity, and transcriptional activity. This suggests that enhancement by VK2 of 5-FU anticancer effects is attributable to inhibition of the NF- $\kappa \mathrm{B}$ activation ordinarily induced by chemotherapeutic agents. Furthermore, dominant-negative IкB $\alpha$ transfection in $\mathrm{HCC}$ cells enhanced 5-FU-induced growth inhibition, again implicating NF- $\mathrm{BB}$ activation in resistance to 5-FU-induced growth inhibition. Like this blockade-inducing transfection, the more attainable VK2-mediated inhibition of $\mathrm{NF}-\mathrm{\kappa B}$ activation by 5 -FU enhanced growth inhibition by a conventional drug. VK2 has not shown any prominent side effects, and safety of longterm oral administration has been proven. In addition to NF$\kappa \mathrm{B}$-related concerns, some advanced HCC tumors harbor p53 mutations that confer chemoresistance (26). Our results showed that VK2 enhanced 5-FU cytotoxicity in cell lines with a variety of forms of p53: wild-type (HepG2), mutant (HLE, Huh7), and null (Hep3B). These data further suggest that usefulness of VK2 as a potential sensitizer for druginduced HCC cell growth suppression when included in combination therapy.

Constitutive activation of NF- $\mathrm{KB}$ which is characteristic of in HCC cells, exerts influence upon a signaling network, that includes expression of cell cycle regulatory genes, antiapoptotic genes, and genes encoding cell surface receptors $(27,28)$. Regulation of these genes by $\mathrm{NF}-\kappa \mathrm{B}$ prevents induction of apoptosis and promotes cell proliferation. Since our results showed VK2 enhanced 5-FU-induced cell growth inhibition through a G1 cell cycle arrest, we examined the expression of cell cycle regulatory proteins after treatment with 5-FU plus VK2. We found that the combination of 5-FU and VK2 induced expression of the Cdk inhibitors p21 and p27 and inhibited expression of cyclin D1. All of these changes block the cell cycle at the G1 checkpoint in contrast to the effect of 5-FU alone. These data are consistent with other previous reports suggesting that induction of cell cycle regulatory proteins is an important part of the anticancer effect of VK2 (29). Cyclin D1 has been suggested to be transcriptionally regulated by $\mathrm{NF}-\kappa \mathrm{B}$ to induce tumor progression through the G1 phase of the cell cycle (30). Indeed, overexpression of cyclin D1, which has been found in human HCC, is sufficient to initiate hepatocarcinogenesis in transgenic mice $(31,32)$. Therefore, as both NF- $\mathrm{KB}$ and cyclin D1 function as oncogenes in the liver, down-regulation

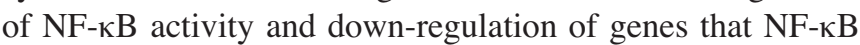
apparently regulates, such as cyclin D1 are likely to be productive molecular goals in HCC treatment. Our results suggested that VK2-mediated cyclin D1 reduction might result from VK2-mediated $\mathrm{NF}-\kappa \mathrm{B}$ inhibition, although additional studies are required to determine conclusively whether cyclin D1 is NF- $\mathrm{BB}$ dependent in our system.

In summary, we demonstrated that VK2 may augment growth inhibition induced by 5-FU in hepatoma cells through inhibition of the NF- $\mathrm{BB}$ signaling pathway, and that combining VK2 with conventional anticancer agents might improve results in the treatment of HCC patients.

\section{Acknowledgements}

This study was supported in part by Grants-in-Aid for Scientific Research from the Ministry of Education, Culture, Sports, Science, and Technology of Japan (to I.O., No. P03346; and to T.M., No. 16590606).

\section{References}

1. Bargou RC, Emmerich F, Krappmann D, Bommert K, Mapara MY, Arnold W, Royer HD, Grinstein E, Greiner A, Scheidereit $\mathrm{C}$ and Dörken B: Constitutive nuclear factorkappaB-RelA activation is required for proliferation and survival of Hodgkin's disease tumor cells. J Clin Invest 100: 2961-2969, 1997.

2. Wang CY, Cusack CJ Jr, Liu R and Baldwin AS Jr: Control of inducible chemoresistance: enhanced anti-tumor therapy through increased apoptosis by inhibition of NF-kappaB. Nat Med 5: 412-417, 1995.

3. Arlt A, Vorndamm J, Breitenbroich M, Fölsch UR, Kalthoff H, Schmidt WE and Schäfer H: Inhibition of NF-kappaB sensitizes human pancreatic carcinoma cells to apoptosis induced by etoposide (VP16) or doxorubicin. Oncogene 20: 859-868, 2001.

4. Wang CY, Mayo MW and Baldwin AS Jr: TNF- and cancer therapy-induced apoptosis: potentiation by inhibition of NFkappaB. Science 274: 784-787, 1996.

5. Yamamoto $\mathrm{Y}$ and Gaynor RB: Therapeutic potential of inhibition of the NF-kappaB pathway in the treatment of inflammation and cancer. J Clin Invest 107: 135-142, 2001.

6. Cusack JC Jr, Liu R, Houston M, Abendroth K, Elliott PJ, Adams $\mathrm{J}$ and Baldwin AS Jr: Enhanced chemosensitivity to CPT-11 with proteasome inhibitor PS-341: implications for systemic nuclear factor-kappaB inhibition. Cancer Res 61: 3535-3540, 2001

7. Hitomi M, Yokoyama F, Kita Y, Nonomura T, Masaki T, Yoshiji H, Inoue H, Kinekawa F, Kurokohchi K, Uchida N, Watanabe S and Kuriyama S: Antitumor effects of vitamins K1, $\mathrm{K} 2$ and $\mathrm{K} 3$ on hepatocellular carcinoma in vitro and in vivo. Int J Oncol 26: 713-720, 2005.

8. Funato K, Miyazawa K, Yaguchi M, Goto A and Ohbayashi K: Combination of 22-oxa-1,25-dihydroxyvitamin $\mathrm{D}(3)$, a vitamin $\mathrm{D}(3)$ derivative, with vitamin $\mathrm{K}(2)$ (VK2) synergistically enhances cell differentiation but suppresses VK2-inducing apoptosis in HL-60 cells. Leukemia 16: 1519-1527, 2002.

9. Yoshida T, Miyazawa K, Kasuga I, Yokoyama T, Minemura K, Ustumi K, Aoshima M and Ohyashiki K: Apoptosis induction of vitamin $\mathrm{K} 2$ in lung carcinoma cell lines: the possibility of vitamin K2 therapy for lung cancer. Int J Oncol 23: 627-632, 2003.

10. Oztopcu P, Kabadere S, Mercangoz A and Uyar R: Comparison of vitamins $\mathrm{K} 1, \mathrm{~K} 2$ and $\mathrm{K} 3$ effects on growth of rat glioma and human glioblastoma multiforme cells in vitro. Acta Neurol Belg 104: 106-110, 2004.

11. Otsuka M, Kato N, Shao RX, Hoshida Y, Ijichi H, Koike Y Taniguchi H, Moriyama M, Shiratori Y, Kawabe T and Omata M: Vitamin K2 inhibits the growth and invasiveness of hepatocellular carcinoma cells via protein kinase A activation. Hepatology 40: 243-251, 2004.

12. Mizuta T, Ozaki I, Eguchi Y, Yasutake T, Kawazoe S, Fujimoto K and Yamamoto K: The effect of menatetrenone, a vitamin K2 analog, on recurrence and survival in patients with hepatocellular carcinoma after curative treatment: a pilot study. Cancer 106: 867-872, 2006. 
13. Habu D, Shiomi S, Tamori A, Takeda T, Tanaka T, Kubo S and Nishiguchi S: Role of vitamin K2 in the development of hepatocellular carcinoma in women with viral cirrhosis of the liver. JAMA 292: 358-367, 2004.

14. Ozaki I, Zhang H, Mizuta T, Ide Y, Eguchi Y, Yasutake T, Sakamaki T, Pestell RG and Yamamoto K: Menatetrenone, a vitamin K2 analogue, inhibits hepatocellular carcinoma cell growth by suppressing cyclin D1 expression through inhibition of nuclear factor kappaB activation. Clin Cancer Res 13: 2236-2245, 2007

15. Zhang H, Morisaki T, Nakahara C, Matsunaga H, Sato N, Nagumo F, Tadano J and Katano M: PSK-mediated NF-kappaB inhibition augments docetaxel-induced apoptosis in human pancreatic cancer cells NOR-P1. Oncogene 22: 2088-2096, 2002.

16. Boucher E, Corbinais S, Brissot P, BoudjemaK and Raoul JL: Treatment of hepatocellular carcinoma (HCC) with systemic chemotherapy combining epirubicin, cisplatinum and infusional 5-fluorouracil (ECF regimen). Cancer Chemother Pharmacol 50: 305-308, 2002

17. Tanioka H, Tsuji A, Morita S, Horimi T, Takamatsu M, Shirasaka T, Mizushima T, Ochi K, Kiura K and Tanimoto M Combination chemotherapy with continuous 5-fluorouracil and low-dose cisplatin infusion for advanced hepatocellular carcinoma. Anticancer Res 23: 1891-1897, 2003.

18. Ikeda M, Okusaka T, Ueno H, Takezako Y and Morizane C: A phase II trial of continuous infusion of 5-fluorouracil, mitoxantrone, and cisplatin for metastatic hepatocellular carcinoma. Cancer 103: 756-762, 2005

19. Stuart K, Tessitore J and Huberman M: 5-Fluorouracil and alpha-interferon in hepatocellular carcinoma. Am J Clin Oncol 19: 136-139, 1996

20. Eguchi H, Nagano H, Yamamoto H, Miyamoto A, Kondo M, Dono K, Nakamori S, Umeshita K, Sakon M and Monden M: Augmentation of antitumor activity of 5-fluorouracil by interferon alpha is associated with up-regulation of p27Kip1 in human hepatocellular carcinoma cells. Clin Cancer Res 6: 2881-2890, 2000 .

21. Kurokawa Y, Matoba R, Nagano H, Sakon M, Takemasa I, Nakamori S, Dono K, Umeshita K, Ueno N, Ishii S, Kato K and Monden M: Molecular prediction of response to 5-fluorouracil and interferon-alpha combination chemotherapy in advanced hepatocellular carcinoma. Clin Cancer Res 10: 6029-6038, 2004.
22. Lamson DW and Plaza SM: The anticancer effects of vitamin K. Altern Med Rev 8: 303-318, 2003.

23. Paris R, Morales A, Coll O, Sanchez-Reyes A, Garcia-Ruiz C and Fernandez-Checa JC: Ganglioside GD3 sensitizes human hepatoma cells to cancer therapy. J Biol Chem 277: 49870-49876, 2002.

24. Chuang SE, Yeh PY, Lu YS, Lai GM, Liao CM, Gao M and Cheng AL: Basal levels and patterns of anticancer drug-induced activation of nuclear factor-kappaB (NF-kappaB), and its attenuation by tamoxifen, dexamethasone, and curcumin in carcinoma cells. Biochem Pharmacol 63: 1709-1716, 2002.

25. Baldwin AS Jr: Control of oncogenesis and cancer therapy resistance by the transcription factor NF-kappaB. J Clin Invest 107: 241-246, 2001.

26. Chan KL and Lung ML: Mutant p53 expression enhances drug resistance in a hepatocellular carcinoma cell line. Cancer Chemother Pharmacol 53: 519-526, 2004.

27. Hsu YL, Kuo PL, Chiang LC and Lin CC: Involvement of p53, nuclear factor kappaB and Fas/Fas ligand in induction of apoptosis and cell cycle arrest by saikosaponin $\mathrm{d}$ in human hepatoma cell lines. Cancer Lett 213: 213-221, 2004.

28. Tai DI, Tsai SL, Chang YH, Huang SN, Chen TC, Chang KS and Liaw YF: Constitutive activation of nuclear factor kappaB in hepatocellular carcinoma. Cancer 89: 2274-2281, 2000.

29. Markovits J, Wang Z, Carr BI, Sun TP, Mintz P, Le Bret M, Wu CW and Wu FY: Differential effects of two growth inhibitory $\mathrm{K}$ vitamin analogs on cell cycle regulating proteins in human hepatoma cells. Life Sci 72: 2769-2784, 2003.

30. Guttridge DC, Albanese C, Reuther JY, Pestell RG and Baldwin AS Jr: NF-kappaB controls cell growth and differentiation through transcriptional regulation of cyclin D1. Mol Cell Biol 19: 5785-5799, 1999.

31. Suzui M, Masuda M, Lim JT, Albanese C, Pestell RG and Weinstein IB: Growth inhibition of human hepatoma cells by acyclic retinoid is associated with induction of p21(CIP1) and inhibition of expression of cyclin D1. Cancer Res 62: 3997-4006, 2002.

32. Deane NG, Parker MA, Aramandla R, Diehl L, Lee WJ, Washington MK, Nanney LB, Shyr Y and Beauchamp RD: Hepatocellular carcinoma results from chronic cyclin D1 overexpression in transgenic mice. Cancer Res 61: 5389-5395, 2001. 